\title{
21- Türkçeyi yabancı dil olarak öğrenen Finlandiyalı öğrencilerin Türkiye ve Türkçe algısı
}

\author{
Haluk GÜNGÖR ${ }^{1}$ \\ Uluhan ÖZALAN ${ }^{2}$
}

APA: Güngör, H.; Özalan, U. (2021). Türkçeyi yabancı dil olarak öğrenen Finlandiyalı öğrencilerin Türkiye ve Türkçe algısı. RumeliDE Dil ve Edebiyat Araştırmaları Dergisi, (25), 336-346. DOI: $10.29000 /$ rumelide.1036554.

$\ddot{O} \mathbf{z}$

Yabancı dil öğretiminde, bireylerin hedef dile ilişkin algılarının belirlenmesi, öğrencilerin tutum, özyeterlik gibi duyuşsal becerileri ve sürecin niteliği açısından önem taşımaktadır. Helsinki Üniversitesi Diller Bölümünde Türkçe öğrenenlerin Türkiye ve Türkçe’ye yönelik algılarının belirlendiği çalışma, nitel araştırma yöntemlerinden olgu bilim (fenomenoloji) desenine uygun olarak yürütülmüştür. Verilerin toplanması aşamasında katılımcılardan, "Türkçe ......... gibidir çünkü........................; Türkiye .............................. gibidir çünkü............................" cümlelerini tamamlamaları istenmiştir. Katılımcıların, Türkiye'ye ilişkin 21; Türkçe’ye ilişkin ise 6 metafor ürettikleri görülmüştür. Bu metaforlardan 2'si olumsuz olarak değerlendirilirken diğer metaforların olumlu metaforlar olduğu gözlenmiştir. Türkiye’ye yönelik metaforlar, yiyecek/gıda, çok kültürlülük, Türklerin özellikleri, tabiat, ev, ön görülemezlik, kültürel köprü, değerli maden ve olumsuz algılar temalarında; Türkçe’ye yönelik algılar ise, Türkçenin özellikleri ve Türkçe öğrenmek temaları altında toplanmıştır. Katılımcıların Türkçe ve Türkiye’ye yönelik algıları genel olarak olumlu iken, bazı olumsuz algıları da bulunmaktadır. Bu ve bunun gibi diğer olumsuz algıların giderilmesi ve olumlu yaklaşımların pekiştirilmesi için ilgili ülkelerde kültürel diplomasi, ortak özelliklere vurgu yapılması, Türkiye'nin daha fazla ve doğru tanıtılması için çeşitli etkinlikler yapılmalıdır. Ayrıca, Türkoloji bölümü desteklenerek Finlandiya'nın diğer üniversitelerinde de bölümün açılması için girişimlerde bulunulmalıdır.

Anahtar kelimeler: Yabancılara Türkçe öğretimi, Finlandiyalı öğrenciler, dil öğretiminde metafor, alg1

\section{The perception of Turkey and the Turkish language of the Finnish students learning Turkish as a foreign language}

\begin{abstract}
Determining the perception of individuals related to the target language is important in terms of the quality of students' attitudes and affective skills such as self-efficacy and of the learning process. The study analyzes the perceptions of the students who have studied at the University of Helsinki, Department of Languages related to Turkey and Turkish. It is conducted in accordance with the phenomenology design which is one of the methods of qualitative research. In order to collect data for the research the students were asked to complete the sentences such as "Turkish is like.....
\end{abstract}

Dr., Gazi Üniversitesi, TÖMER (Ankara, Türkiye), halukgungor1@gmail.com, ORCID ID: oooo-0oo2-4111-4106 [Araştırma makalesi, Makale kayıt tarihi: 26.10.2021-kabul tarihi: 20.12.2021; DOI: 10.2900o/rumelide.1036554] Dr., Helsinki Üniversitesi, Edebiyat Fakültesi, Altayistik Çalışmaları (Helsinki, Finlandiya), uluhanoz@hotmail.com, ORCID ID: 0000-0002-9865-6010

Adres
RumeliDE Dil ve Edebiyat Araştırmaları Dergisi Osmanağa Mahallesi, Mürver Çiçeği Sokak, No:14/8 Kadıköy - ISTANBUL / TÜRKIYE 34714 e-posta: editor@rumelide.com tel: +90 $5057958124,+902167730616$
Address

RumeliDE Journal of Language and Literature Studies Osmanağa Mahallesi, Mürver Çiçeği Sokak, No:14/8

Kadıköy - ISTANBUL / TURKEY 34714

e-mail: editor@rumelide.com,

phone: +90 5057958124, +90 2167730616 


\begin{abstract}
because.........."; "Turkey is like........, because.....................". The students have produced 21 metaphors related to Turkey and 6 metaphors to Turkish. It has been observed that two of the metaphors have negative connotations, whereas the rest of them were positive metaphors. It has been found out that that the metaphors related to Turkey are in the themes of food, multi-culturalism, the properties of the Turkish people, nature, unpredictability, cultural bridge, precious metal and negative perception. The perceptions as to Turkish are in the themes of the properties of the Turkish language and learning Turkish. While the perceptions of the participants are generally positive towards Turkey, there are some negative perceptions, as well. In order to remove these kinds of negative perceptions and to reinforce positive attitudes cultural diplomacy, emphasizing common values and some more activities introducing Turkey in a better way are required. Besides, by supporting the departments of Turkology, in the other universities of Finland, the department must be initiated.
\end{abstract}

Keywords: Teaching Turkish to foreigners, Finnish students, metaphor in language teaching, perception

\title{
Giriş
}

Yabancı/ikinci dil öğretimi sürecinin izlenmesi ve değerlendirilmesi, sürecin düzenlenmesi, aksayan yönlerin belirlenip düzeltmelerin yapılabilmesi, öğretim faaliyetlerinin iyileştirilmesi ve geliştirilmesi açısından büyük önem taşımaktadır. Bu izleme/değerlendirme faaliyetlerinden biri, öğrencilerin algılarının belirlenerek hedef dilin onlar için ne anlama geldiğinin belirlenmesidir. Çünkü hem öğreticiler hem öğrenciler sınıf ortamına dil öğrenme görevinin doğası hakkındaki inançlarıyla yakından ilgili tutumlara, deneyimlere ve beklentilere dayalı karmaşı bir dizi değişkeni sınıf ortamına getirmektedir (Riley, 2009). Doğrudan gözlenemeyen ve ölçülemeyen bu karmaşık ögeler, bireylerin ürettikleri metaforlar ile somutlaştırılarak bu metaforlardan bir sonuca ulaşılması hedeflenmektedir.

Metafor kavramını Demirci (2016: 330), "Yunanca meta- 'öte' ve pherein 'taşımak, götürmek' ikilisinin birleşmesinden oluşmakta olup 'nakletmek, öteye taşımak'” anlamlarına geldiğini belirtmektedir. Lakoff \& Johnson'a göre (2005: 147) metaforlar, bir şeyi başka bir şey ile anlamamızı sağlar. Burada kastedilen kelime odaklı değil, kavramlarla metafor üretilmesi, böylece birey tarafından o özelliğin nasıl nitelendirildiğinin belirlenmesidir.

Low (2008: 226), metafor/metaforlaştırmanın, çok eski zamanlardan beri eğitimi kolaylaştırmak için kullanıldığını belirterek zihni ve eleştirel düşünmeyi geliştirmede, problem çözmeyi teşvik etmede, sınıflandırma ve ezberlemede yardımcı olduğunu vurgulamaktadır. Bu yönüyle, öğrencilerin metafor geliştirmeleri, onların zihinlerindeki algılarını yansıtmanın yanı sıra düşünme becerilerini de geliştirmektedir. Alanyazındaki araştırmalar metafor üretiminin, başarıyı neden bu kadar kalıcı bir şekilde etkilediğini kanıtlamaya çalışmaktadır. Çeşitli alanlarda araştırmalara konu olan metafor, dil öğretiminde bilişsel dilbilimde uzun süre önce çalışılmaya başlanmıştır. 1980'li yıllardan itibaren ise uygulamalı dilbilim alanında güçlü bir araç haline gelmiştir (Low, 2003: 239). Eğitim araştırmalarında metaforlar genellikle meta-analizler, sistematik gözlemler, kavramlar arasında metaforlarla ilgili modeller kurularak, “ benim için .drr.” şeklinde formlarla belirlenmektedir (Littlemore \& Low, 2006; Akkaya, 2013; Fang, 2015; Boylu \& Işık, 2017; Karatay \& Kartallığlu, 2019; Uçak, 2017). Yabancı/ikinci dil öğrenimine yönelik yapılan araştırmalarda da bu durum gözlenmektedir. Hoang (2014:2), metaforik farkındalığın önemini vurgulayarak bu farkındalığın dil becerilerinin gelişimini de olumlu yönde etkileyeceğini, bilişsel dilbilimi temel alarak belirtmektedir. Yabancı dil

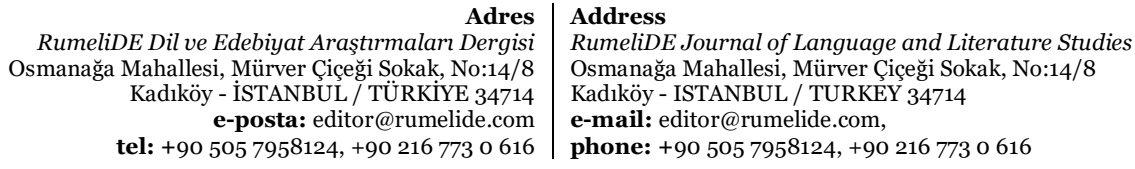


The perception of Turkey and the Turkish language of the Finnish students learning Turkish as a foreign language / H. Güngör; U. Özalan (pp. 336-346)

öğretimi sürecinde bireylerin hedef dile ilişkin geliştirdikleri algıları, onların duyuşsal özelliklerinin olumlu/olumsuz olması ile yakından ilgilidir. Olumlu algı, özyeterlik düzeyini de olumlu etkileyecek, böylelikle bireylerin daha başarılı olmaların sağlayacaktır. Bu açıdan bakıldığında, Türkçeyi yabancı dil olarak öğrenenlerin metaforik algılarının belirlenmesi, öğrencilerin Türkiye ve Türkçe’ye olan bakış açlarını doğrudan etkilediğinden, özellikle öğreticilere sınıf içerisinde ışık tutacaktır. Bu araştırmanın da çalışma grubunu oluşturan Finlandiya gibi ülkelerde az sayıda Türkçe öğrencisinin olduğu göz önünde bulundurulursa, Finlandiyalıların Türkçe ve Türkiye algılarının bilinmesi, onların daha fazla ilgilerinin çekilmesi, yaşadıkları sorunların en aza indirilmesi gibi hususlar açısından önemlidir.

Finlandiya, özellikle 19.yüzyılın sonları ve 20. yüzyllın başlarından itibaren Türkçe ve Türkoloji çalışmalarının dünyadaki en önemli merkezlerinden biri olmuştur. Türkçe ve Türkoloji’nin Finlandiya'da ilgi gösterilen alanlardan biri olmasının sebebi Finlandiyalı bilim adamlarının kendi tarihini araştırmak amacıyla Orta Asya ve Sibirya'ya yaptıkları bilimsel gezilerde Türk topluluklarıyla ve Türklerin bıraktıkları eserlerle karşılaşmış olmalarıdır. Finlandiya, 13. yüzyılın başlarından 1809 yılına kadar İsveç Krallığı idaresinde kalmış, sonrasında 1809 yılında Çarlık Rusya tarafından işgal edilmiştir. Finlandiya'nın 1917 yılında bağımsızlı̆̆ına kavuşmasının ardından bilim adamları, Fin tarihini ve kültürünü araştırmaya girişmişler, bu arayışlarında Türkler, Moğollar, Tunguzlar ve Samoyedler gibi halklarla karşlaşmışlar, milletlerinin tarihini, dilini ve kültürlerini bu halklarla ilişkilendirerek incelemeye başlamışlardır. Bu sebeple Finlandiya'da ve özellikle Helsinki Üniversitesi’nde Türkoloji çalışmaları yoğun olarak yürütülmüştür. Burada yetişen ve çalışan Matthias Alexander Castén, Otto Donner, Gustaf John Ramstedt, Martti Räsänen, Pentti Aalto, Juha Antero Janhunen gibi önemli Altayistler, bir dönem Helsinki Üniversitesi’ni dünyada Altayistik çalışmalarının zirve noktası haline getirmiştir.

Aslında çalışmalarını burada yürüten bilim adamlarının hiçbiri -Martti Räsänen dışında-, araştırmalarının odak noktasına doğrudan Türk dili ve Türkoloji'yi koymamıştır. Finlandiya'da Türkoloji ve Türk dili çalışmaları daha çok Altayistiğin bir kolu olarak gelişmiştir. Castén, Ramstedt gibi önemli bilim adamlarının yaptığı karşılaştırmalı çalışmalar burada Altay dilleri kuramının temellerini oluşturmuş, böylece Türk dilleri Moğol, Tunguz, Ural dilleri ile yapılan karşılaştırmalı çalışmaların konusu olmuştur. Bu nedenle Türkçe öğretiminin ve konu ile ilgili yapılan araştırmaların, Finlandiya'da ve Helsinki Üniversitesi’nde köklü bir geleneği vardır.

Burada yürütülen Türkçe ve Türkoloji derslerinden başka, Fin-Ugor topluluğu (Suomalais-Ugrilainen Seura), daha çok geçmişte faaliyet yürüten Fin Arkeoloji topluluğu gibi bilimsel kuruluşların yaptıkları çalışmalarda da Türkçe ve Türkoloji kendine bir yer bulmaktadır. Ayrıca, yine Finlandiya'da yayımlanan Studio Orientalia, Journal de la Société Finno-Ougrienne gibi saygın bilimsel dergilerde de Türkçe ve Türkoloji ile ilgili makaleler yayımlanmaktadır.

Türkçe öğretiminin de Finlandiya'da köklü bir geçmişi vardır. Bazı kesintiler olsa da kayıtlarda 1855 yllından beri Türkçenin burada öğretildiği görülmektedir. Helsinki Üniversitesi’nde Türkçe derslerini yürütenler ve bu dersleri hangi ylllarda verdiklerine dair bilgiler Halén'e göre (1990: 51-52) şu şekildedir:

1855-1856 (Herman Kellgren), 1858 (Lagus Wilhelm), 1864-1865 (Lagus Wilhelm), 1870-1871 (Ernst Strandman), 1874-1875 (Ernst Strandman), 1889-1890 (Ernst Strandman), 1891-1892 (Ernst Strandman), 1896-1897 (Ernst Strandman), 1898-1899 (Tallqvist Knut), 1907-1908 (Gustaf John Ramstedt), 1927-1930 (Martti Räsänen), 1933-1949 (Martti Räsänen), 1949-1955 (Martti Räsänen),

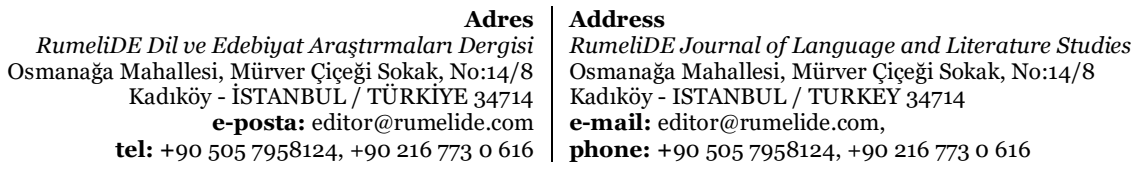


1955-1956 (Martti Räsänen), 1956-1959 (Martti Räsänen), 1960-1961 (Martti Räsänen), 1963-1977 (Ymär Daher), 1977-1978 (Ymär Daher, Emine Gürsoy-Naskali), 1978-1980 (Ymär Daher, Emine Gürsoy-Naskali), 1980-1982 (Ymär Daher, Emine Gürsoy-Naskali), 1982-1984 (Ymär Daher, Emine Gürsoy-Naskali), 1984-1987 (Pirkko Tokat), 1987-1988 (Pirkko Tokat, Ymär Daher), 1988-199o (Pirkko Tokat, Sonja Bulut).

Eski Türkçe dersleri ise 1914 yllından başlamak üzere belirli dönemlerde Helsinki Üniversitesi'nde yürütülmüş̧ür;

1914 (Gustaf John Ramstedt), 1916 (Gustaf John Ramstedt), 1919 (Gustaf John Ramstedt), 1930-1931 (Gustaf John Ramstedt), 1933-1937 (Martti Räsänen), 1941-1942 (Gustaf John Ramstedt), 1944-1946 (Martti Räsänen), 1947-1950 (Martti Räsänen), 1951-1953 (Martti Räsänen), 1954-1959 (Martti Räsänen), 1960-1961 (Martti Räsänen), 1964-1965 (Pentti Aalto), 1969-1970 (Pentti Aalto), 1974-1977 (Harry Halén), 1981-1982 (Harry Halén), 1989-1990 (Harry Halén).

Buna ek olarak Tatarca, Çuvaşça, Uygurca, Yakutça gibi Türk dilleri de Helsinki Üniversitesi’nde öğretilmiştir.

Tatarca 1907 (Heikki Paasonen), 1937 (Gustaf John Ramstedt), 1946-1947 (Martti Räsänen), 19511952 (Martti Räsänen), 1953-1954 (Martti Räsänen), 1966-1979 (Ymär Daher), 1979-1986 (Ymär Daher), 1986-1987 (Ymär Daher), 1987-1989 (Ymär Daher);

Uygurca 1919 (Gustaf John Ramstedt);

Kigizca 1916 (Gustaf John Ramstedt), 1933 (Gustaf John Ramstedt);

Yakutça 1932 (Gustaf John Ramstedt), 1934 (Gustaf John Ramstedt), 1939-1941 (Gustaf John Ramstedt), 1946-1948 (Gustaf John Ramstedt), 1950-1951 (Gustaf John Ramstedt), 1952-1953 (Gustaf John Ramstedt);

Çuvaşça 1941-1946 (Martti Räsänen), 1950-1951 (Martti Räsänen), 1952-1959 (Martti Räsänen), 19601961 (Martti Räsänen), 1966 (Heikki Paasonen, Pentti Aalto), 1967 (Pentti Aalto), 1972 (Pentti Aalto);

Karşılaştırmalı Türk Dilleri 1916-1917 (Gustaf John Ramstedt), 1932-1933 (Gustaf John Ramstedt), 1937-1939 (Martti Räsänen), 1944-1947 (Martti Räsänen), 1947-1948 (Martti Räsänen), 1948-1950 (Martti Räsänen), 1953-1955 (Martti Räsänen),

Son dönemlerde ise Türkçe dersleri (Türkçe 1 ve Türkçe 2), Helsinki Üniversitesi, Edebiyat Fakültesi Diller Bölümünde, Türkiye Cumhuriyeti Milli Eğitim Bakanlı̆̆ı tarafından görevlendirilen okutmanlar tarafından yürütülmektedir. Ayrıca, lisansüstü öğretim yapan Altayistik çalışmaları bölümünde 2018 ylında Karşılaştırmalı Türk Dilleri (Ses bilgisi), 2019'da Eski Türkçe, 2020'de Çağatayca dersleri yürütülmüştür. 2021 yllında ise Osmanlıca ve Özbekçe dersleri okutulmaktadır. Yine kendisi bir Finlandiya Tatarı olan ve Finlandiya Tatar topluluğu onursal başkanı Okan Daher aynı bölümde Tatarca dersleri vermektedir.

Helsinki Üniversitesi Altayistik çalışmaları bölümü, alanında dünyanın sayılı bölümlerinden olmakla birlikte son yıllarda eski etkinliğinden uzaktır. Volker Rybatzki'nin 2018'de vefatı ve Prof. Dr. Juha Janhunen'in 2019 yılında emekli olmasından sonra Altayistik çalışmaları bölümünde yeni

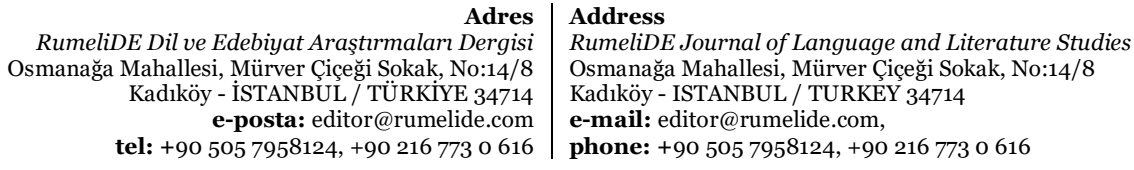


araştırmacılar istihdam edilmemiştir. $\mathrm{Bu}$ nedenle, Altayistik bölümünün bir parçası olarak karşılaştırmalı Altay dilleri, Moğolca, Tunguzca gibi dersler artık Helsinki Üniversitesinde verilmese de, Türkoloji ile ilgili yukarıda anılan dersler son yıllarda da okutulmaya devam etmektedir.

\section{Yöntem}

Araştırma, nitel araştırma yöntemlerinden olgu bilim (fenomenoloji) desenine uygun olarak yürütülmüştür. Olgu bilim araştırmaları, "insanların fenomeni nasıl algıladıkları, nasıl betimledikleri, hakkında ne hissettikleri, nasıl yargıladıkları, nasıl anımsadıkları, nasıl anlamlandırdıklar ve diğerleri ile onun hakkında nasıl konuştuklarina odaklantr." (Patton, 2014: 104). Deneyimlere odaklanan olgu bilim, "etkili, duygusal ve sıklkkla yoğun insan deneyimlerini çalışmak için uygun" (Merriam, 2013: 26) bir yaklaşım olarak kabul edilmektedir. Bu araştırmada, Finlandiyalı öğrencilerin, Türkiye ve Türkçeye yönelik deneyimlerinden hareketle, bu iki olguya ilişkin ne hissettikleri, ne düşündükleri, yani olumlu ve olumsuz algıları, oluşturdukları metaforlar aracılığı ile belirlenmiştir. Bu nedenle araştırmada olgu bilim (fenomenolojik) yönteminden yararlanılmıştır. Finlandiyalı öğrencilerin, Türkiye ve Türkçeye yönelik olumsuz algıları da belirlenerek bunları iyileştirmeye yönelik çözüm önerileri geliştirilmiştir.

\section{Çalışma grubu}

Araştırmanın çalışma grubunu 2020-2021 eğitim-öğretim yllında Helsinki Üniversitesi Modern Diller Bölümünde Türkçe öğrenen 7 öğrenci oluşturmaktadır. Bölümde öğrenim gören öğrenci sayısının 20 olduğu göz önünde bulundurulduğunda, ulaşılan sayı önemli bir büyüklüğü temsil etmektedir. Ayrıca, çalışma grubunun Finlandiya'da öğrenim görenlerden oluşması çalışma grubunun benzersizliği açısından da oldukça önemlidir. Çalışma grubu, seçkisiz olmayan örnekleme yöntemlerinden uygun örnekleme yöntemine (convenience sample) göre belirlenmiştir. Uygun örneklem yöntemi olasılıklı olmayan, örneklem gruba kolay ulaşılabilen, az maliyetli bir yöntemdir (Schonlau, Fricker ve Elliot, 2002: 8-9).

Araştırmanın çalışma grubu 3 kadın, 4 erkek öğrenciden; dört A1, bir A2, bir B1 ve bir B2 öğrencisinden oluşmaktadır. Öğrencilerin 4'ü lisans 3’ü de yüksek lisans öğrencisidir.

\section{Veri toplama süreci}

Araştırmanın verileri, araştırmacılar tarafından hazırlanan kişisel bilgi formu ile öğrencilerin Türkiye ve Türkçe algılarına ilişkin metaforlarını üretebilmelerine yönelik hazırlanan form aracılı̆̆ ile toplanmıştır. Araştırma verilerinin toplanması için hazırlanan formlar, öğrencilerin Türkçe düzeyleri farklılık gösterdiğinden (A1-A2-B1-B2) İngilizce hazırlanmıştır. Öğrencilere Türkiye’ye yönelik metafor üretmeleri için, "Please write your ideas about Turkey using metaphors. (For example; I think Turkey is (like) a/an bridge because it combines two edges.)" ; Türkçe'ye yönelik algılarının belirlenmesi için, "Please write your ideas about Turkish using metaphors. (For example; I think Turkey is (like) a/an bridge because it combines two edges.)" şeklinde açı uçlu iki soru yöneltilerek cevaplamaları istenmiştir.

Hazırlanan form, COVID-19 sürecinde yüz yüze görüşme yapma imkânı olmadığından, dijital ortama aktarılarak Google Forma dönüştürülmüştür. Dijital ortamdaki formlar, bölümdeki 20 öğrencinin epostalarına ayrı ayrı gönderilerek formlardaki sorulara cevap vermeleri beklenmiştir. Ancak 20 öğrencinin tamamı araştırmaya katılmamıştır. Araştırmaya katılım gönüllülük esasına dayalı

Adres Address

RumeliDE Dil ve Edebiyat Araştırmaları Dergisi $\quad$ RumeliDE Journal of Language and Literature Studies Osmanağa Mahallesi, Mürver Çiçeği Sokak, No:14/8 $\quad$ Osmanağa Mahallesi, Mürver Çiçeği Sokak, No:14/8 Kadıköy - ISTANBUL / TURKIYE 34714 Kadıköy - ISTANBUL / TURKEY 34714 e-posta: editor@rumelide.com $\quad$ e-mail: editor@rumelide.com, tel: +90 505 7958124, +90 216773 o 616 phone: +90 505 7958124, +90 2167730616 
olduğundan 7 öğrenci formu doldurarak elektronik ortamda araştırmacılara ulaştırmıştır. Bu veriler üzerinde analizler yapılarak bulgulara ulaşılmıştır.

\section{Verilerin analizi}

Araştırmada ulaşlan veriler içerik analizi yöntemi ile çözümlenmiştir. İçerik analizi ile olgu bilim deseninde yapılan araştırmalarda elde edilen veriler tanımlanabilmektedir (Yıldırım ve Şimşek, 2006: 75). Öğrencilerin elektronik ortamda doldurdukları formlar iki alan uzmanı tarafından ayrı ayrı incelenmiştir. Her iki uzman öncelikle verilerdeki metaforları belirlemiştir. Birbirine benzeyen metaforlar aynı kategoride kodlanarak tekrar sıklıkları hesaplanmıştır. Böylece, verilerin hangi temalar altında toplandığı da belirlenmiştir.

\section{Bulgular}

Araştırma sürecinde elde edilen veriler analiz edilerek bulgulara ulaşılmıştır. Bulgular, iki araştırma sorusu altında toplanmıştır. Finlandiyalı öğrencilerin Türkiye ve Türkçeye yönelik algılarından hareketle oluşturdukları metaforlar ve bu metaforların gerekçeleri aşağıda verilmiştir.

Birinci araştırma sorusu: Katılımcllar Türkiye’ye ilişkin algılarını hangi metaforlarla açılamaktadır?

Tablo 1. Finlandiyalı öğrencilerin Türkiye’ye ilişkin ürettikleri metaforlar.

\begin{tabular}{|l|l|l|}
\hline Tema & Metafor & $\boldsymbol{f}$ \\
\hline Yiyecek/Gıda & Kebap, tatl, baharat, soğan & 4 \\
\hline Çok Kültü̈rlülük & $\begin{array}{l}\text { Gece ve gündüz, farklı renkler ve } \\
\text { duygular, zengin kültür, mozaik }\end{array}$ & 4 \\
\hline Türklerin Özellikleri & $\begin{array}{l}\text { Sicak kalpli insanlar, cömert, } \\
\text { nezaket, açlk sözlü, gerçek } \\
\text { (dürüst/samimi) }\end{array}$ & 5 \\
\hline Tabiat & Orman & 1 \\
\hline Ev & Maket ev & 1 \\
\hline Ön Görülemezlik & Kahve falı, labirent & 2 \\
\hline Kültürel Köprü & $\begin{array}{l}\text { Asya-Avrupa/Kuzey-Güney } \\
\text { arasinda köprü }\end{array}$ & 1 \\
\hline Değerli Maden & İnci & 1 \\
\hline Olumsuz Algılar & Demanslı bir babaanne, sansür & 2 \\
\hline Toplam & & 21 \\
\hline
\end{tabular}

Tablo 1 incelendiğinde, Finlandiyalı öğrencilerin Türkiye'ye yönelik 9 tema altında toplam 21 metafor ürettikleri görülmektedir. Metaforların Yiyecek/Gıda (4), Çok kültürlülük (4), Türklerin özellikleri (5), Tabiat (1), Ev (1), Ön görülemezlik (2), Kültürel köprü (1), Değerli maden (1) ve Olumsuz algılar (2) temalarında toplandığı görülmektedir. Üretilen 21 metafordan yalnızca biri olumsuzdur. Bu metaforların 4'ünün "Yiyecek/Gıda” teması altında toplandığı görülmektedir. Buna yönelik metaforlar ise kebap, tatl, baharat ve soğandır. Katılımcıların bu tema altında verdikleri cevaplar şu şekildedir:

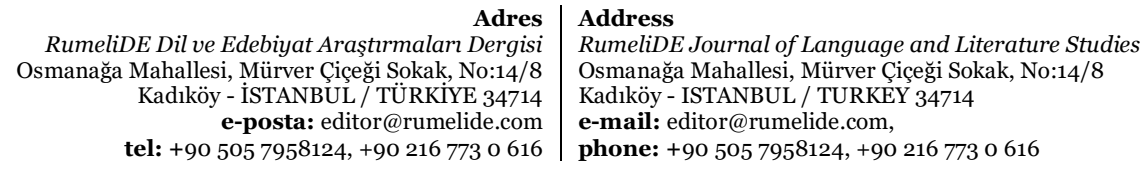


The perception of Turkey and the Turkish language of the Finnish students learning Turkish as a foreign language / H. Güngör; U. Özalan (pp. 336-346)

(K 1): "Türkiye bir kebap gibidir, çünkü çok çeşitli stilleri, baharatları ve tatları kapsar ve fikirleri böler.”

(K 4): “Türkiye’nin tüm katmanları nedeniyle soğan gibi olduğunu düşünüyorum.” Bu ifadeler katılımclların, Türkiye'nin birçok farklılığa sahip olduğunu düşündüklerini ve bu farklılıkların bir araya gelerek güzel bir ülke oluşturduğu görüşüne sahip olduklarını göstermektedir.

“Çok kültürlülük” teması altında gece ve gündüz, farkh renkler ve duygular, zengin kültür, mozaik metaforları olmak üzere 4 metafor üretildiği görülmektedir. Katılımcıların bu temaya yönelik verdikleri cevapları şu şekildedir:

(K 4): "Bence Türkiye, içindeki farkllıklardan dolayı gece ve gündüz gibidir."

(K 6): “Türkiye'nin birçok rengi ve hissi var."

(K 6): "Türkiye’yi düşündüğümüzde zengin bir kültür, sıcak kalpli insanlar, cömertlik ve nezaket algısı alyyorum. Öte yandan, onları tanıdığınızda insanlar çok açık sözlü ve gerçektir."

(K 7): “Türkiye bir mozaik gibidir çünkü sayısız farkl ülke ve kültürün ortassndadır.” Bir önceki temada olduğu gibi, bu temada da öğrenciler Türkiye'nin barındırdığı farklılıkları vurgulamışlardır. Türkiye'nin gece ve gündüz gibi birbirine zıt olan düşünceleri barındırdığını, zengin bir kültüre ev sahipliği yaptığını vurgulayan katılımcılar, Türk insanını açık sözlü, nezaket sahibi, sıcak kalpli insanlar olarak görmektedirler.

"Türklerin özellikleri" olarak belirlenen tema altında sıcak kalpli insanlar, cömertlik, nezaket, açı sözlü, gerçek (dürüst/samimi) olmak üzere 5 farklı metafor üretildiği belirlenmiştir. Katılımcıların bu temaya yönelik cevapları şu şekildedir:

(K 6): "Türkiye’yi düşündüğümüzde zengin bir kültür, sıcak kalpli insanlar, cömertlik ve nezaket algısı alyorum. Öte yandan, onları tanıdığınızda insanlar çok açık sözlü ve gerçektir.”

Katılımcılar bu görüşleriyle, Türklerin açık sözlü, dürüst, sıcakkanlı, cömert insanlar olduğunu ve zengin bir kültüre sahip olduklarını belirtmişlerdir.

"Tabiat" teması altında katılımcılar yalnızca orman metaforunu üretmişlerdir. Katılımcıların buna yönelik verdikleri cevap şu şekildedir:

(K 6): “Türkiye bir orman gibidir, oradan her şeyi bulabilirsiniz." Bilindiği gibi ormanlar, bünyesinde birçok farklı canlıya ev sahipliği yapan, canllara hayat veren bir yapıdır. Katılımcılar Türkiye'yi bir ormana benzeterek ülke içerisinde birçok farklı kesimin hayat bulduğu ve çeşitli imkânlara sahip olduğunu vurgulamışlardır.

“Kültürel köprü” temasına yönelik Asya-Avrupa / Kuzey-Güney arasında bir köprü şeklinde bir adet metafor üretilmiştir. Buna yönelik verilen cevap aşağıdadır:

(K 7): “Türkiye bir köprü gibidir. Çünkü doğu ile batı (ve aynı zamanda güney ile kuzey) arasındadır." Katılımclların bu ifadesi ile Türkiye'nin yalnızca doğu-batı arasında değil, kuzey-güney arasında da bir köprü işlevi olduğu vurgulanmıştır.

Katılımcıların verdikleri cevaplardan biri, "Değerli maden” teması altında değerlendirilmiştir. Buna yönelik verilen cevap aşağıdadır:

(K 1): “Türkiye, dış itibarından çok daha parlak olduğu için kabuğuyla kaplanmış bir incidir.” Bu ifade ile katılımcı, Türkiye'nin aslında olduğundan daha güçlü, daha önemli ve değerli olduğunu belirtmiştir. Ancak bir inci gibi, kabuğunun altında bütün bu değerlerin gizlendiğini vurgulamıştır.

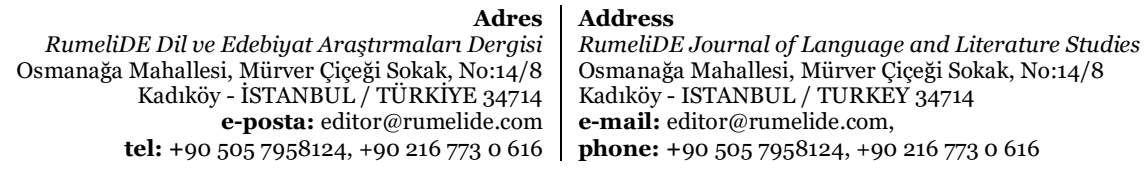


Katılımcılar tarafından üretilen metaforlardan ikisi "Olumsuz algılar" teması altında değerlendirilmiştir. Buna yönelik cevaplar aşağıdadır:

(K 5): "Türkiye demanslı bir büyükanne gibidir: Birçok torunu (etnik köken) vardır, ancak hepsine aynı adla (Türk) hitap eder.

(K 3): "Türkiye ikiyüzlü, çünkü sansürle denetlenmesine rağmen ifade özgürlüğü olduğunu iddia ediyor."

Olumsuz görüşler incelendiğinde ise, Türkiye'de yaşayan toplulukların tamamına neden "Türk" denildiğinin sorgulandığı ve yadırgandığı görülmektedir. Ayrıca, düşünce özgürlüğünün olduğu bir ülke olmasına rağmen sansürün denetleyici bir mekanizma olarak kullanıldığı da vurgulanmaktadır.

İkinci araştırma sorusu: Katılımcılar Türkçe’ye ilişkin algılarını hangi metaforlarla açılamaktadır?

Tablo 2. Finlandiyalı öğrencilerin Türkçe’ye ilişkin ürettikleri metaforlar.

\begin{tabular}{|c|c|c|}
\hline Tema & Metafor & $f$ \\
\hline Türkçenin Özellikleri & $\begin{array}{l}\text { Dolmuş gibidir, şiir gibi, şarkı gibi, } \\
\text { tahta veya lego blokları }\end{array}$ & 4 \\
\hline Türkçe Öğrenmek & Engebeli bir yol, kapı & 2 \\
\hline \multicolumn{2}{|l|}{ Toplam } & 6 \\
\hline
\end{tabular}

Tablo 2 incelendiğinde, Finlandiyalı öğrencilerin Türkçe'ye yönelik 2 tema altında toplam 6 metafor ürettikleri görülmektedir. Metaforların Türkçenin özellikleri (4) ve Türkçe öğrenmek (2), temalarında toplandığı görülmektedir. Üretilen 6 metafor içinde olumsuz metafor bulunmamaktadır. Katılımcılar tarafından “Türkçenin özellikleri” temasına yönelik 4 metafor üretilmiştir. Buna yönelik verilen cevaplar şu şekildedir:

(K 5): “Türk dili bir dolmuş gibidir. Tam minibüs-cümlenin dolu olduğunu düşündüğünüzde her zaman bir son ek-yolcu için yer vardir.

(K 3): “Türkçe müzik ya da şür gibidir. Çünkü ünlüler ve ünsüzler uyum içinde olmak zorundadır.”

(K 6): “Türkçe bir şür gibidir ve kulağa bir şarkı gibi gelir. Bunu duymak çok hoş bir şey.”

(K 1): "Türkçe, tahta bloklar veya lego blokları gibidir. Çünkü kelimeleri tamamlamak için farkh küçük ögelerden kelimeler inşa edersiniz." Katılımcıların “Türkçe”ye yönelik görüşleri incelendiğinde sondan eklemeli bir dil olmasının kullanıcıları açısından önemli bir kolaylık sağladığı; Türkçe'nin ses uyumları açısından müzik ya da şiir gibi kulağa hoş geldiği; ayrıca küçük sayılabilecek eklerin, seslerin anlam kurma sırasında önemli işlevlere sahip oldukları ve bu yönüyle oldukça önemli oldukları görüşü ön plana çıkmaktadır.

“Türkçe öğrenmek” temasına yönelik iki metafor üretilmiştir. Buna yönelik cevaplar şu şekildedir:

(K 2): "Bence Türkçe bir kapı gibidir. Çünkü başka bir kültüre açılır."

(K 4): "Türkçe öğrenmenin engebeli bir yolda ilerlemeye benzediğini düşünüyorum. Çünkü öğrenmesi bazen kolay bazen zor.” Katılımcllar bu görüşleriyle, Türkçe ile yeni bir dünyaya giriş yapabileceklerini, Türkçe öğrenmenin zor ve kolay yönlerinin olduğunu belirtmişlerdir.

\section{Tartışma ve sonuç}

Katılımcıların, Türkiye’ye yönelik 21 metafor ürettiği ve bu metaforların ikisinin ( $\left.\mathrm{K}_{3} ; \mathrm{K}_{5}\right)$ olumsuz olduğu sonucuna ulaşlmıştır. Üretilen metaforların, Türkiye'nin zengin kültürü, Türk insanının

\footnotetext{
Adres | Address

RumeliDE Dil ve Edebiyat Araştırmalar Dergisi Osmanağa Mahallesi, Mürver Çiçeği Sokak, No:14/8 Kadıköy - ÍSTANBUL / TÜRKIYE 34714 e-posta: editor@rumelide.com tel: +90 505 7958124, +90 2167730616

RumeliDE Journal of Language and Literature Studies Osmanağa Mahallesi, Mürver Çiçeği Sokak, No:14/8

Kadıköy - ISTANBUL / TURKEY 34714

e-mail: editor@rumelide.com,

phone: +90 5057958124 , +90 2167730616
} 
The perception of Turkey and the Turkish language of the Finnish students learning Turkish as a foreign language / H. Güngör; U. Özalan (pp. 336-346)

özellikleri, yemek, coğrafí açıdan köprü niteliği taşıması, ev gibi temalar altında toplandı̆̆ı belirlenmiştir. Uçak (2017), Iraklı öğrencilerin Türkiye algılarını incelediği çalışmasında, Iraklı öğrencilerin Türk halkını "hoşgörülü” olarak tanımladıklarını, katılımcıların Türkiye’yi “çok kültürlü bir merkez” olarak gördüklerini belirlemiştir. Ayrıca, Yiğit (2021) tarafından Saraybosnalı öğrencilerin Türkiye algılarının belirlenmesine yönelik yapılan çalışmanın bulgularına göre, öğrencilerin önemli bir bölümü, “Türkiye'yi ve Türk kültürünü takdir ediyorum” maddesinde yoğunlaşmıştır (Yiğit, 2021: 214). Karatay ve Kartallığlu (2019) tarafindan yapılan araştırmada da, Türkiye'de öğrenim gören Moğol öğrencilerin Türkiye’ye yönelik olumlu metaforlar geliştirdikleri; yani olumlu algıya sahip oldukları belirlenmiştir. Araştırmaya katılan Finlandiyalı öğrencilerin de bu yönde metafor geliştirdikleri düşünüldüğünde, araştırmanın bulgularının benzer çalışmaların bulguları ile örtüştüğü görülmektedir. Türkiye'de öğrenim görmemelerine rağmen böyle bir algıya sahip olmaları ayrıca önemlidir.

K5, Türkiye'de birçok farklı etnik grubun yaşadığını ve bu etnik grupların tamamına "Türk" denildiğini ifade ederek bunu, demans hastası bir babaanne metaforu ile açıklamıştır. Diğer etnik grupların unutulduğunu ima etmiş ve bunun ancak unutkanlık ile mümkün olabileceğini belirtmiştir. $\mathrm{K}_{3}$ ise, Türkiye'de sansürün bulunduğunu ancak bunun inkâr edildiğini savunarak, Türkiye’yi “iki yüzlü” olarak nitelemiştir.

Finlandiyalı öğrencilerin Türkiye ve Türkçe algıları incelendiğinde, bu algıların yemek, kültür, Türk insanının ve Türkçe’nin özellikleri ile Türkçe öğrenmek gibi temalar altında toplandığı görülmektedir. Katılımcıların, Türkiye'nin ekonomik durumu, uluslararası güç, ordu-millet anlayışı, uluslararası ortamlardaki etkinliği gibi konulara ilişkin herhangi bir metafor üretmedikleri görülmektedir. Bozkuş ve Arı (2017) tarafından Ermenistan, Gürcistan ve Azerbaycanlı öğrencilerin Türkiye algıları üzerine yaptıkları çalışmalarında, öğrencilerin \%77,5’i Türkiye’ye gelmeden önce Türkiye'yi, dünyadaki konumu açısından güçlü bir ülke olarak değerlendirirken, Türkiye'de bir süre yaşadıktan sonra bu düşüncelerinin \%56,6’ya gerilediği belirlenmiştir. Yabancı öğrencilerin Türkiye’ye geldikten sonraki algıları farklılık gösterse de Türkiye'nin konumu açısından güçlü bir ülke olduğu her iki durumda da ön plana çıkmaktadır. İlgili bazı çalışmaların (Uçak, 2017; Göver \& Yavuzer, 2015; Yirik, Uslu ve Küçük, 2015) Irak, Suriye gibi yakın coğrafyadan gelen yabancı uyruklular ile gerçekleştirildiği düşünüldüğünde, Türkiye’ye yönelik algının, daha önceden Türkçeyi bilme, Türkleri tanıma gibi aşinalık durumlarına bağlı olduğu düşünülebilir. Ancak ülkeye gelmeden önce, Türk kültürüne, Türkçe’ye ve Türklere aşina olmanın, ülke imajı üzerinde etkisinin bulunmadığı yapılan çalışmalarla belirlenmiştir (Kahraman, 2018: 108-109). Finlandiyalı öğrencilerin, Türkiye’nin gücüne ya da bölgesindeki durumuna yönelik herhangi bir metafor üretmemeleri, Finlandiyalıların bir ülkenin askeri, siyasi gücüne çok fazla önem vermedikleri şeklinde yorumlanabilir. Bu durum, Finlandiyalı öğrencilerin, Türkiye ve Türkçe'ye yönelik, bu temalarda herhangi bir algılarının olmadığını; başka bir deyişle Türkiye'yi bu alanlarda yeterince tanımadıklarını göstermektedir. Boylu ve Işık (2017) çalışmalarında, uluslararası öğrencilerin Türkçeye ilişkin algılarını diller arası benzerlik, olumlu his, ihtiyaç ve kolay bulma temaları altında toplamıştır. Çalışma grubunu çeşitli milletlere mensup 100 öğrencinin oluşturduğu ilgili çalışma ile bu çalışmanın sonuçları genel olarak örtüşmemektedir. Bu durumun arasında, Finlandiya'nın sosyo-ekonomik, eğitim ve daha birçok açıdan gelişmiş bir ülke olması, Türkçe ve Türkiye’ye yeterince ilgi duyulmaması gibi nedenler sayılabilir.

Katılımcıların Türkçeye yönelik 2 tema altında toplam 6 metafor ürettikleri belirlenmiştir. Bu metaforların 5’i olumlu 1'i ise olumsuzdur. Türkiye’ye yönelik 21 metafor üretilirken, Türkçe’ye yönelik 6 metafor üretilmesi, katılımcıların Türkiye’ye daha çok ilgi duyduğu şeklinde yorumlanabilir. Ülkeye olan bu ilgi ve merak duygusunun, onları Türkçe öğrenmeye yönelttiği düşünülmektedir. Akkaya (2013)

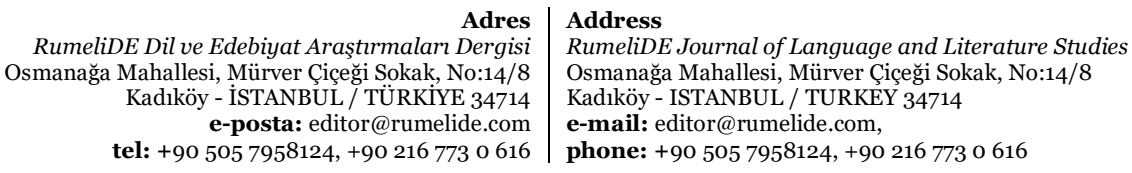


Suriyeli mültecilerin Türkçe algılarını incelediği çalışmasında, Suriyelilerin \%96,2'sinin olumlu metafor geliştirdiğini belirlemiştir. Çalışma grubunun Türkçe’ye yönelik geliştirdiği metaforların, kendi ülkelerinden göçe zorlanmaları nedeniyle biraz daha duygusal metaforlar (ev, anne vb.) geliştirdikleri görülmektedir. Karatay (2016: 71) Türkiye’de yaşayan Iraklı öğrencilerin Türkçe algılarını incelediği çalışmasında, öğrencilerin olumlu algıya sahip olduklarını belirlemiştir. Bu algıyı oluşturan metaforların da Suriyeli öğrencilerle benzerlik taşıdı̆̆ı görülmektedir. Finlandiyalı katılımcıların ise Türkçenin sondan eklemeli bir dil olması ( $\mathrm{K}_{5}$ : dolmuş metaforu vb.) gibi yapısal özelliklerine yoğunlaştıkları görülmektedir. Yani Finlandiyalı öğrencilerin, Türkçe'ye yönelik duygusal algılarının en azından yoğun bir şekilde olmadığını söylemek mümkündür.

Çeşitli ülkelerden Türkiye’ye öğrenim görmek için gelen Sakarya Üniversitesindeki 13 öğrencinin Türkçe'ye yönelik algıları, Gürbüz ve Güleç (2016) tarafından metaforlar aracılı̆̆ ile incelenmiştir. Katılımcılar, Türkçenin sondan eklemeli bir dil olmasının, onların Türkçe öğrenme süreçlerini olumsuz etkilediğini ifade etmişlerdir. Ancak bu durum, Finlandiyalı öğrenciler için olumlu bir yapısal özelliktir. K5’in ürettiği dolmuş metaforu, Türkçenin her zaman bir son ek ile bittiği düşünülen kelime, fiil veya diğer ögelerin devam ettirilebileceğini göstermektedir. Araştırma, bu yönüyle, diğer çalışmalardan farklılaşmaktadır. Bu durumun en önemli nedenleri arasında, Fincenin de sondan eklemeli bir dil olması gösterilebilir. Tipolojik olarak Altay dilleri ile benzerlikler gösteren Fincede, Türkçede olduğu gibi, yapım ve çekim morfolojisi son ekler aracılığıyla gerçekleşir. Buna hâl kategorisinden bir örnek vermek gerekirse; talo (ev), talo-on (ev-e), talo-ssa (ev-de), talo-sta (ev-den) (Karlsson 2012: 110-112). İki dil arasındaki bu benzerlik, öğrencilerin daha kolay Türkçe öğrenmesinde etkili olacaktır. İki öğrenci ise, Türkçe öğrenmeyi engebeli bir yol ve kapı metaforlarıyla tanımlamıştır.

Yabancı dil öğretiminde algı çalışmaları 1980'li yıllardan itibaren artan bir ilgiye sahiptir. Türkçenin yabancı dil olarak öğretiminde bireylerin algılarının belirlenmesi, öğretim sürecinin düzenlenmesi, öğreticilerin yetiştirilmesi, ders araç-gereçlerinin hazırlanması gibi birçok konuda yol gösterici olacaktır. Özellikle ülkelere yönelik Türkçe öğretimi politikalarının geliştirilmesinde bu tür çalışmalar ilgililere yol gösterici olacaktır.

\section{Kaynakça}

Akkaya, A. (2013). Suriyeli mültecilerin Türkçe algıları. EKEV Akademi Dergisi. 17(56), 179-190.

Boylu, E. \& Işık, Ö. F. (2017). Türkçeyi yabancı dil olarak öğrenenlerin Türkçeye yönelik algılarının metaforlar aracılığı ile belirlenmesi. Ana Dili Eğitimi Dergisi. 5(3), 450-471.

Bozkuş Deveci, Y. \& Arı Bekci, E. (2017). Güney Kafkasya kökenli öğrencilerin Türkiye’ye gelmeden önceki ve geldikten sonraki Türkiye algılarının değişimi. Bostancı Kırtasiye \& Matbaacılık.

Demirci, K. (2016). Metafor: Bir anlatım ve üretim mekanizması. M. Sarıca, B. Sarıca (Ed.) Dil bilimleri kültür ve edebiyat içinde (s. 330-343). Ankara: Padam Yayınları.

Fang, S. (2015). College EFL learners' metaphorical perceptions of English learning. The Journal of Asia TEFL. 12(3), 61-79.

Göver, İ. H. \& Yavuzer, H. (2015). Kayseri'de öğrenim gören yabancı uyruklu öğrencilerin Kayseri, Türkiye ve İslam algısı. Turkish Studies. 10/2, 1025-1050.

Gürbüz, R. \& Güleç, İ. (2016). Türkiye'de eğitim gören yabancı öğrencilerin Türkçeye ilişkin görüşleri: Sakarya Üniversitesi örneği. Sakarya University Journal of Education. 6/2, 141-153.

Halén, H. (1990). Janua Orientis : luettelo Aasian ja Afrikan kielten ja kulttuurien opettajista ja opetuksesta Turun Akatemiassa sekä Helsingin yliopistossa 1640-1990. Helsinki: Helsingin Yliopisto.

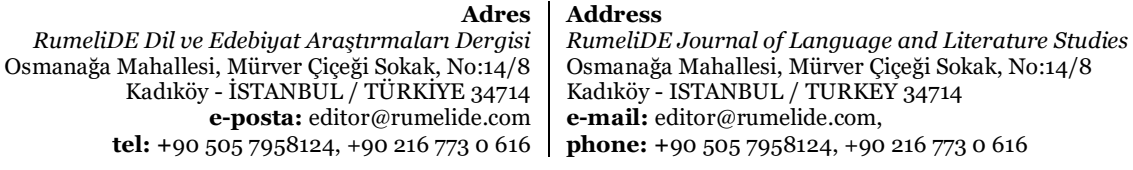


Hoang, H. (2014). Metaphor and second language learning: The state of the field. The Electronic Journal for English as a Second Language. 18(2), 1-27.

Kahraman, E. (2018). Türkiye bursları ile İstanbul'a eğitime gelen öğrencilerin Türkiye’ye aşinalıkları ile Türkiye imajı ve kişiliği algısı ilişkisi. İstanbul Arel Üniversitesi İletişim Çalışmaları Dergisi. 6/13, 67-112.

Karatay, H. (2016). Iraklı öğrencilerin Türkiye ve Türkçe metaforu. Yeni Türkiye. 22(84), 69-72.

Karatay, H. \& Kartallığlu, N. (2019). Moğol öğrencilerin Türkiye ve Türkçe algıları. Bolu Abant İzzet Baysal Üniversitesi Eğitim Fakültesi Dergisi. 19(3), 1016-1028.

Karlsson, F. (2002). Finnish: An essential grammar. London: Routledge.

Lakoff, G. \& Johnson, M. (2005). Metaforlar: Hayat, anlam ve dil. (G. Y. Demir Çev.). İstanbul: Paradigma Yayıncllk.

Littlemore, J. \& Low, G. (2006). Metaphoric competence and communicative language ability. Applied Linguistics. 27(2), 268-294.

Low, G. (2003). Validating metaphoric models in applied linguistics. Metaphor and Symbol. 18(4), 239254.

Low, G. (2008). Metaphor and education. R. M. Gibbs (Ed.), The Cambridge handbook of metaphor and thought, içinde (s. 212-231). New York: Cambridge University Press.

Merriam, S. B. (2013). Nitel araştırma: Desen ve uygulama için bir rehber. (3. Baskı). (S. Turan, Çev.). Ankara: Nobel Yayıncllı.

Patton, M. Q (2014). Nitel araştırma ve değerlendirme yöntemleri (3. Baskı). (M. Bütün \& S. B. Demir, Çev. Ed.). Ankara: Pegem Akademi.

Riley, P. A. (2009). Shifts in beliefs about second language learning. RELC Journal. 4O(1), 102-124.

Schonlau, M., Frıcker, R. D. \& Ellıot, M. N. (2002). Conducting research surveys via e-mail and the web. Santa Monica: RAND Publications.

Uçak, S. (2017). Irak’ta yabancı dil olarak Türkçe öğrenen öğrencilerin Türkiye, Türkler ve Türkçe algısı. Turkish Studies. 12/14, 491-512.

Yıldırım A. \& Şimşek, H. (2006). Sosyal bilimlerde nitel araştırma yöntemleri. Ankara: Seçkin Yayınevi.

Yiğit, M. (2021). Saraybosna Yunus Emre Enstitüsündeki kursiyerlerin Türkiye algısı ve Türkçe öğrenme sebepleri. Kırıkkale Üniversitesi Sosyal Bilimler Dergisi. 11/1, 207-216.

Yirik, Ş., Uslu, A. \& Küçük, F. (2015). Yerleşik yabancıların Türkiye’ye ilişkin sosyo kültürel algılarının demografik özelliklerine göre incelenmesi. Bartın Üniversitesi İ. İ. B. F. Dergisi. 6/11, 263-282.

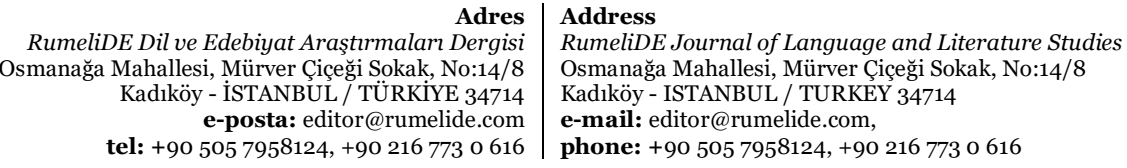

